\title{
Spinal Dysraphism of a Baby - A Case Report
}

\author{
TAHER MA ${ }^{\mathrm{a}}$, SULTANA J ${ }^{\mathrm{b}}$, SHARIF MM도 ALAM MMUd $^{\mathrm{d}}$, RAHMAN MT ${ }^{\mathrm{e}}$, SHEGUFTA F ${ }^{\mathrm{f}}$, ABEDIN $\mathrm{N}^{\mathrm{g}}$
}

\begin{abstract}
:
A 8 months old male child reported to paediatric OPD of Shaheed Suhrawardy Medical College Hospital with the complaints of small swelling in the back and tilting of body on one side during sitting and standing posture. His antenatal period was unremarkable, post natal period revealed delayed crying and immunization was not completed. Local examination showed a small hairy patch in lower dorsal region. General and systemic examination revealed no significant abnormality. Consulting physician advised to do $X$ - ray of dorso- lumbar spine (both views), Ultrasonography (USG) of the swelling and FNAC from the swelling. $X$ - ray report concluded as spinal dysraphism with widening of spinal canal. Ultrasonography showed dural ectasia. No malignant or granulomatous cells were found in FNAC. For confirmation of plain $x$ - ray and USG
\end{abstract}

Introduction:

Spinal dysraphism is defined as congenital anomalies of spine and spinal cord. ${ }^{1}$ Diastematomyelia refers to a type of spinal dysraphism when there is a longitudinal split in the spinal cord. ${ }^{2}$ Split cord malformations are a congenital abnormality and account for approximately $4 \%$ of all congenital spinal defects. ${ }^{3}$ The majority of patients with diastematomyelia are symptomatic, presenting with signs and symptoms of tethered cord, although patients will mild type II variety may be minimally affected or entirely asymptomatic. ${ }^{4}$ Presenting

a. Dr. Md. Abu Taher, Associate Professor, Department of Radiology \& Imaging, BIRDEM, Dhaka

b. Dr. Jafreen Sultana, Associate Professor, Department of Radiology \& Imaging, BIRDEM, Dhaka

c. Dr. Md. Mofazzal Sharif, MD Student, Department of Radiology \& Imaging, BIRDEM, Dhaka

d. Dr. Md. Mohit Ul Alam, SMO, Department of Radiology \& Imaging, BIRDEM, Dhaka

e. Dr. Md. Towhidur Rahman, MO, Department of Radiology \& Imaging, BIRDEM, Dhaka

f. Dr. Farzana Shegufta, Senior Consultant, Department of Radiology \& Imaging, BIRDEM, Dhaka

g. Dr. Naffisa Abedin, Assistant Professor, Department of Radiology \& Imaging, BIRDEM, Dhaka

Correspondence: Dr. Md. Abu Taher, Associate Professor, Department of Radiology \& Imaging, BIRDEM, Dhaka, E-mail: mataherdr67@gmail.com

Received: 15 March, 2013, Accepted: 22 December, 2014 findings, the patient's parent was advised to do MRI of dorsolumbar spine in Radiology and Imaging Department of BIRDEM hospital. MRI findings were compatible with Diastematomyelia with tethered cord as evidenced by two unequal hemicord separated by signal void cleft and low insertion of spinal cord at L4-L5 level. As MRI is less sensitive regarding bone, $C T$ scan was done and $C T$ revealed grossly abnormal vertebral bodies with an osseous spur traversing the entire canal dividing the canal into two halves. Spinal cord was also divided into two unequal cord. Considering X-ray, USG CT and MRI, final Diagnosis was made as Type I Diastematomyelia with Tethered cord.

Key words: Spinal dysraphism, Diastematomyelia, Tethered cord.

(Birdem Med J 2015; 5(1): 42-45)

symptoms include leg weakness, low back pain, scoliosis and incontinence. Patients with diastematomyelia also frequently have other associated annomalies including meningocele, neuroenteric cyst, dermoid, club foot, spinal cord lipoma and haemangioma overlying spine. ${ }^{5}$ In type I diastematomyelia there is duplicated dural sac, with common midline spur and usually these patients are symptomatic. In type II diastematomyelia there is single dural sac containing both hemicords and less symptomatic. Type I is the classic diastematomyelia and in these patients hydromyelia is common. Midline spur is often present (osseous or osteocartilaginous) with vertebral abnormalities like hemivertebrae, butterfly vertebrae, spina bifida or fusion of laminae of adjacent levels. Skin pigmentation, haemangioma, hypertrichosis (hair patch) are common and patients are usually symptomatic presenting with scoliosis and tethered cord syndrome. In type II there is usually no bony spur or septum but non osseous spur divides the cord, sometimes incompletely. Hydromyelia may be present. Spina bifida sometimes may be present, but other vertebral anomalies are far less common. Split cord malformations are more common in the lower cord but can sometimes occur at multiple levels. $50 \%$ occur between L1 and L3, 25\% occur between T7 and T12. An associated bony, cartilagenous or fibrous spur projecting through the dura mater, forwards from the 
neural arch, is visible in $33 \%$ of cases. ${ }^{2}$ Vertebral anomalies (spina bifida, butterfly or hemivertebrae) are common. Laminar fusion associated with a neural arch defect is a good predictor of diastematomyelia and occur at the level of the defect, or at an adjacent level. Plain film may show multi- level spina bifida, widening of interpedicular distance but this may be remote from the site of the spur, as associated scoliosis and anteroposterior narrowing of vertebral bodies. CT is able to better image many of the features seen on plain films and in addition may demonstrate the bony septum. Modern scanners are also able to visualise the cord. MRI is the modality of choice for assessing children with split cord malformations. As well as being able to elegantly demonstrate the cord and presence of hydromyelia (if present), it can also assess for the presence of the numerous associated anomalies. Usually there is little in the way of a differential diagnosis when the cord has been adequately imaged and features are typical. ${ }^{7}$

\section{Case Report:}

A 8 months old male child (Figure 1) hailing from Savar, Dhaka was brought to paediatric OPD of Shaheed Suhrawardy Medical College Hospital with the complaints of small hairy nevus on lower dorsal region. The patient had tilting of body on one side during sitting and standing posture. No history of consanguinity was noted. Patient's parent did not give any history of back pain, limb weakness and incontinence of urine. His antenatal period was unremarkable, post natal period revealed delayed crying and immunization was not completed. Local examination showed hairy blackish patch on lower dorsal region. General and systemic examination revealed no significant abnormality. Then the attending physician advised to do X-ray dorsolumbar spine (both views), Ultrasonography of the swelling and FNAC from the swelling. X-ray dorso lumbar spine A/P and lateral views showed (Figure 2) kypho-scoliosis, multi level spina bifida, widening of interpedicular distance, fusion of L3, L4 and L5 vertebrae, bony spicule at L3-L4 level and widening of spinal canal. $\mathrm{X}$ ray report concluded as spinal dysraphism with widening of spinal canal. Ultrasonography showed small area of soft tissue echogenicity in lower dorsal region with dilatation of dural spaces and was concluded as dural ectasia. FNAC findings revealed adipose tissue fragment admixed with lymphocyte in a haemorrhagic background without any malignant or granulomatous cells. For confirmation of plain $\mathrm{x}$-ray and USG findings the patient's partent was told to do MRI of D/L spine in Radiology and Imaging Department of BIRDEM hospital. MRI findings (Figure 3) were expansion of spinal canal, enlargement of dural spaces, low lying spinal cord up to L4-L5 level, splitting of spinal cord by a signal void cleft (bony) from D12-L1 up to L3-L4 level and central canal dilatation with CSF filled cavity at D9D10 level. MRI report was compatible with Diastematomyelia (Split Spinal cord) with tethered cord (low lying cord) and dural ectasia. As MRI could not differentiate between Type I and Type II

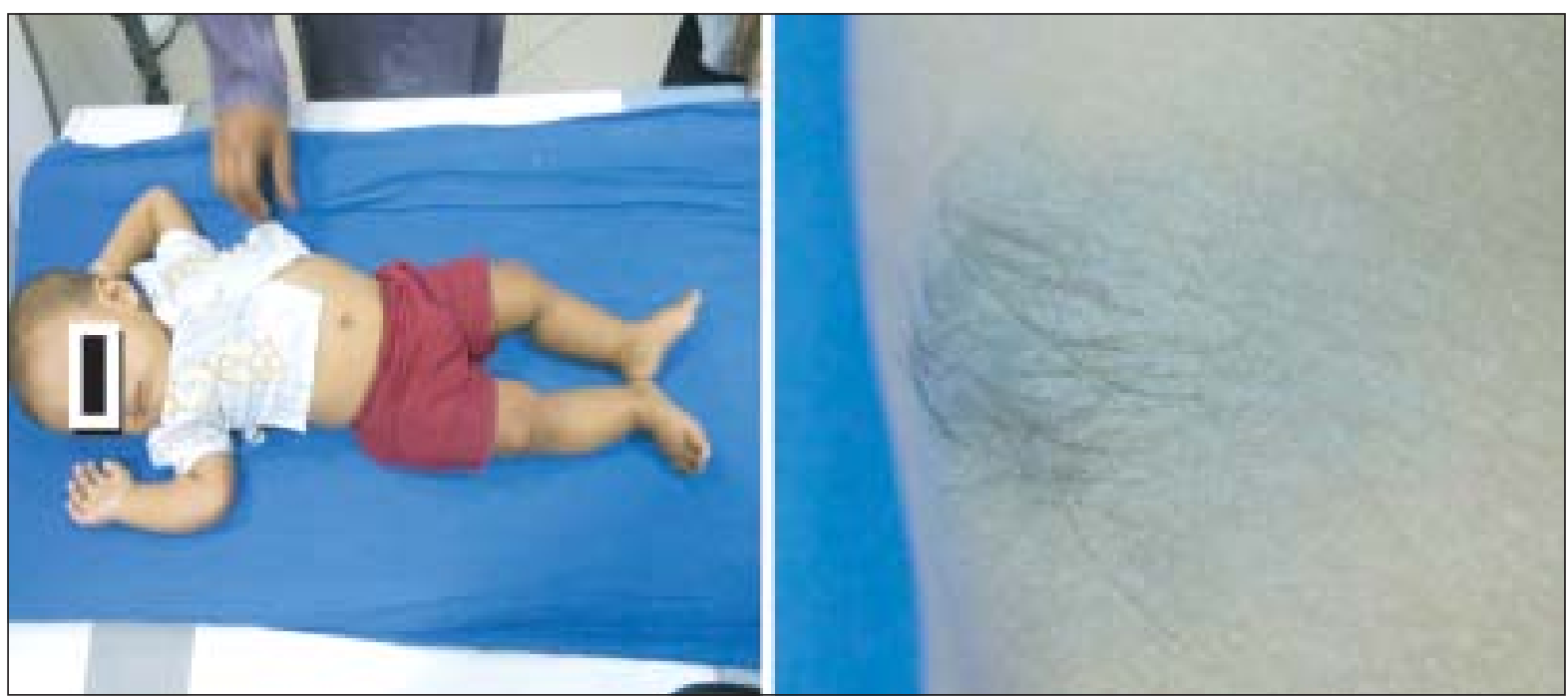

Fig.-01: Photograph of the patients (With Parents' consent) and hairy nevus on dorsal aspect. 

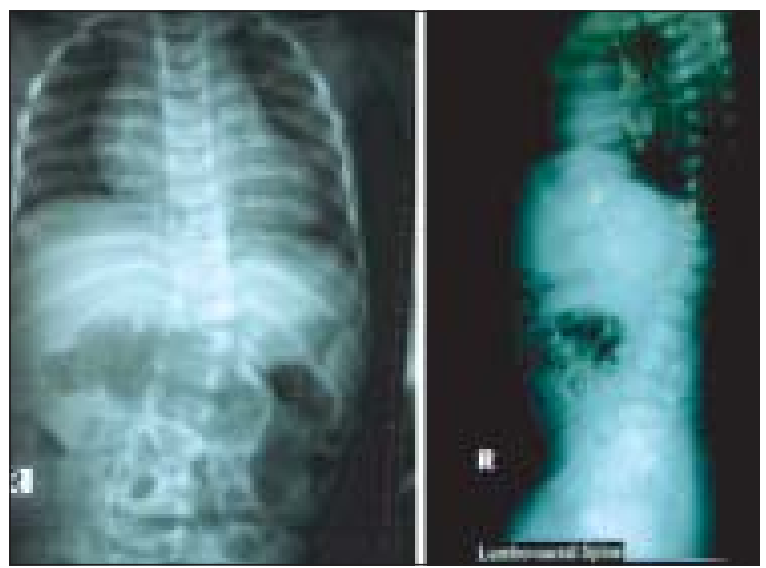

Fig.-2: $X$ ray dorso lumbar spine A/P and lateral views showing Kypho-scoliosis, multi level spina bifida, widening of interpedicular distance, fusion of L3, L4 and L5 vertebrae, bony spicule at L3-L4 level and widening of spinal canal.

Diastematomyelia, CT scan was done and CT scan revealed (Figure 4) grossly abnormal vertebral body with an osseous spur traversing the entire canal dividing the canal into two halves. Spinal cord was also divided into two complete parts. Considering X-ray, USG, CT and MRI, final Diagnosis was Type I Diastematomyelia with Tethered cord.

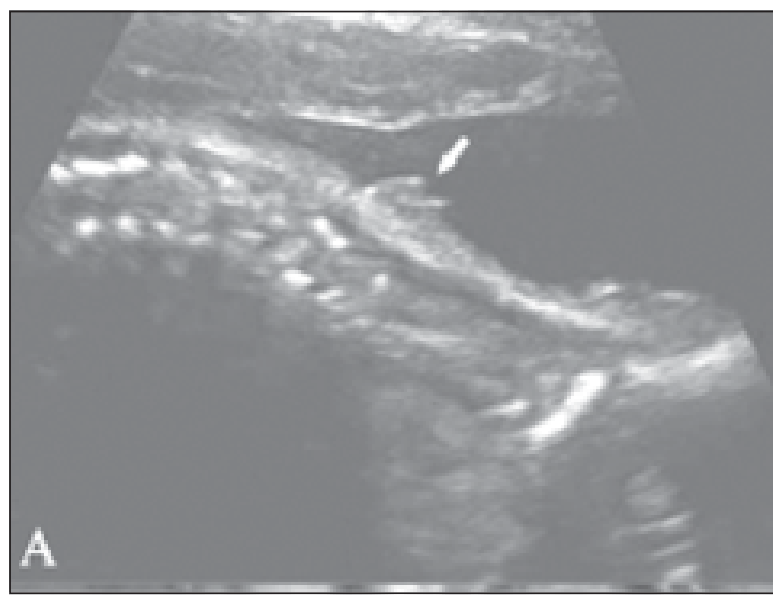

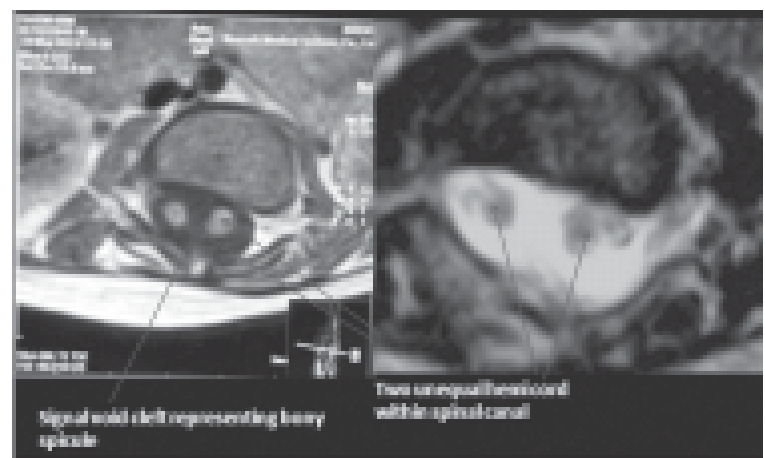

Fig.-03: Axial T1WI and T2WI MRI images.

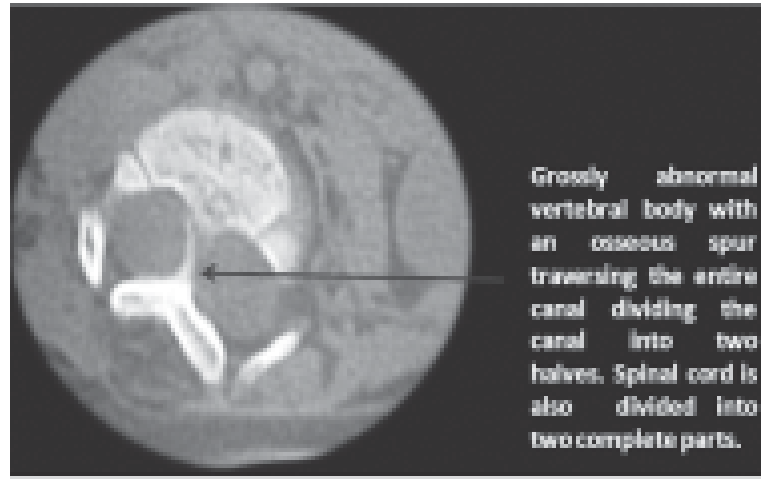

Fig.-04: Non contrast axial CT scan at L3 level (bone window).

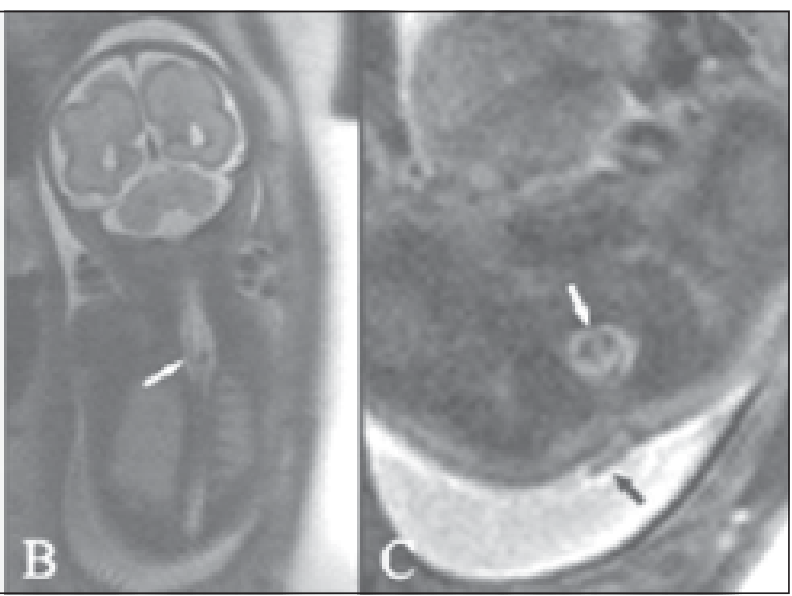

Fig-05: Antenatal USG showing echogenic element in dorsal aspect of foetal spine and MRI showing hydromyelia with splitted cord in Diastematomyelia.

\section{Discussion:}

Diastematomyelia was initially described as split notochord syndrome (Spina bifida oculta), where developmentally there is longitudinal split of spinal cord. ${ }^{2,5}$ Another closely related condition Diplomyelia is encountered with this condition where cord is splitted into two halves from cervical region. ${ }^{3}$ In Diastematomyelia cord is duplicated mainly at lumbar 
region. After duplication again they may be united or may be separated. In our present case the cord was splitted by a bony spur at D12-L1 level and united at lower L3-L4 level. Majority of the subjects with type I presented with leg weakness, low back pain, scoliosis and incontinence. In our case, no associated symptoms except scoliosis were noted as patient was only 8 months old. In type I Diastematomyelia, hydromyelia is common. Midline spur is often present with vertebral abnormalities like spina bifida or fusion of laminae of adjacent levels. Our study subject had almost all the findings which were revealed in X-ray, CT scan and MRI. Tethered cord and hydromyelia are common associated abnormality with type I Diastematomyelia. ${ }^{4,6}$ These were found in our present case. One important imaging aspect should be noticed from this particular case that MRI can diagnose this case but can not characterize it as type I or II. For detailed information regarding bone, CT scan is more sensitive than MRI and CT scan revealed the bony spur and classified it as type I Diastematomyelia. This anomaly can be diagnosed antenatally by ultrasonography and MRI (Figure 5). Ante natal ultrasonography during anomaly scan plays an important role in early detection of spinal dysraphism as evidenced by presence of an extra echogenic element in the midline of foetal spine and widening of posterior elements. Foetal MRI is also an important modality used in antenatal period for intrauterine detection.
Amniocentesis with estimation of AFP and Acetyl cholinesterase concentration also play role in early diagnosis. ${ }^{3,7}$

Tethered cord implies a low lying conus medullaris and thick filum terminale greater than $2 \mathrm{~mm}$ in diameter. Here restriction of cord movement and traction occur during vertebral development resulting in neurological deficits. $^{8}$

\section{References:}

1. Stephanie L, Ibrahim M, Chharles A, Hermant A. Congenital spine and spinal cord malformation. Am J Roentgenol 2010;194:26-37.

2. Basauri L, Palma A, Zuleta A, Holzer F, Poblete R. Diastematomyelia.Acta -neurochirurgica 1979; 51: 91-96.

3. Arredondo F, Haughton VM, Hemmy DC et-al. The computed tomographic appearance of the spinal cord in diastematomyelia. Radiology 1980; 136 (3): 685-88.

4. Williams RA, Barth RA. In utero sonographic recognition of diastematomyelia. Am J Roentgenol 2005; 144 (1): 87-88.

5. Özek MM, Cinalli G, Maixner WJ. The Spina Bifida, Management and Outcome. Springer Verlag. 2008.

6. Anderson NG, Jordan S, Macfarlane MR et-al. Diastematomyelia: diagnosis by prenatal sonography. Am J Roentgenol 1994; 163 (4): 911-14.

7. Naidich TP, Harwood-nash DC. Diastematomyelia: hemicord and meningeal sheaths; single and double arachnoid and dural tubes. Am J Neuroradiol 4 (3): 633-36.

8. Venkataramana NK. Spinal dysraphism.Journal of Paediatric Neuroscience 2011; 6(1):31-40. 